\title{
Kajian Pengelolaan Hutan Pinus Di Taman Nasional Kerinci Seblat Resort Rejang Lebong
}

\author{
NASIP IRIANTO ${ }^{1}$, ENGGAR APRIYANTO ${ }^{2}$, MUHAMMAD FAIZ BARCHIA ${ }^{3}$ \\ 1. Dinas Lingkungan Hidup Kabupaten Lebong Email: nasipirianto77@yahoo.com \\ 2. Jurusan Kehutanan Universitas Bengkulu Email: enggavan@yahoo.com \\ 3. Jurusan Ilmu Tanah Universitas Bengkulu Email: faiz_barchia@yahoo.com
}

\begin{abstract}
ABSTRAK
Penelitian ini bertujuan untuk menilai indeks dan status keberlanjutan dan mengidentifikasi atribut-atribut yang sensitif dalam sistem pengelolaan hutan pinus di Taman Nasional Kerinci Seblat Resort Rejang Lebong. Indeks dan status keberlanjutan pengelolaan hutan pinus dinilai dari dimensi ekologi, ekonomi, sosial budaya, teknologi dan infrastruktur, dan hukum dan kelembagaan. Metode analisis data keberlanjutan yang digunakan dalam pengelolaan hutan pinus di Taman Nasional Kerinci Seblat (TNKS) Resort Rejang Lebong adalah Multi Dimensional Scaling (MDS) yang kemudian diberi nama RAP-TNKS (Rapid Appraisal for Pinus on TNKS) yang hasilnya dinyatakan dalam bentuk nilai indeks dan status keberlanjutan. Identifikasi atribut-atribut yang sensitif terhadap indeks dan status keberlanjutan dari masing-masing dimensi melalui Analisis Leverage dan Monte Carlo. Hasil penelitian menunjukkan bahwa indeks multidimesi status keberlanjutan pengelolaan hutan pinus di Taman Nasional Kerinci Seblat Resort Rejang Lebong sebesar 56,14 (cukup berkelanjutan). Nilai indeks keberlanjutan dari dimensi ekologi $(64,23)$, dimensi ekonomi $(51,95)$, dimensi sosial budaya $(54,72)$ dan dimensi hukum dan kelembagaan $(74,97)$ masuk ke dalam kategori baik dengan status cukup berkelanjutan, sedangkan dimensi teknologi dan infrastruktur $(34,81)$ berada pada kategori kurang dengan status kurang berkelanjutan.
\end{abstract}

Kata Kunci: indeks dan status keberlanjutan, pinus, TNKS, MDS

\section{PENDAHULUAN}

Secara ekologis hutan mempunyai peranan penting dalam mendukung kelangsungan hidup di bumi antara lain dalam pengaturan tata air, perlindungan tanah, mempengaruhi kondisi iklim dan melindungi plasma nutfah. Kenyataan ini menghendaki keberadaan hutan harus tetap dipertahankan. Namun demikian, sejalan dengan pertambahan penduduk, tekanan terhadap sumber daya hutan akan semakin meningkat (Supriadi, 2011).

Selama ini pengelolaan hutan konservasi hanya terfokus kepada aspek ekologis saja, dan kurang memperhatikan aspek ekonomi dan aspek sosial. Pengelolaan hutan lestari mengupayakan terjadinya efisiensi ekonomi, ekologi dan sosial dari sumberdaya hutan. Oleh sebab itu hutan harus dipandang sebagai modal, faktor produksi, ekosistem, dan ruang sehingga pengelolaan hutan dapat memberikan manfaat secara optimal kepada seluruh stakeholder.

Pemanfaatan hutan termasuk hasil hutan bukan kayu di dalamnya bertujuan untuk memperoleh manfaat yang optimal bagi kesejahteraan seluruh masyarakat secara berkeadilan dengan tetap menjaga kelestariannya. Pemanfaatan hutan yang berlebihan akan mengakibatkan berubahnya fungsi hutan tersebut. Oleh karena itu juga diperlukan suatu arahan pengelolaan khususnya pada tegakan pinus di TNKS Resort Rejang Lebong, agar dapat dimanfaatkan secara optimal untuk kesejahteraan masyarakat dengan tetap menjaga kelestariannya. 
Penelitian ini dalam rangka mengetahui status keberlanjutan pengelolaan hutan pinus pada zona pemanfaatan Taman Nasional Kerinci Seblat Resort Rejang Lebong menggunakan analisis keberlanjutan dengan lima dimensi yaitu ekologi, ekonomi, sosial budaya, teknologi dan infrastruktur, serta hukum dan kelembagaan.

Beberapa permasalahan yang berkenaan dengan kajian pengelolaan hutan pinus di Taman Nasional Kerinci Seblat Resort Rejang Lebong adalah sebagai berikut:

1. Bagaimana indeks dan status keberlanjutan pengelolaan hutan pinus di Taman Nasional Kerinci Seblat Resort Rejang Lebong?

2. Atribut-atribut apa saja yang sensitif berpengaruh terhadap keberlanjutan pengelolaan hutan pinus di Taman Nasional Kerinci Seblat Resort Rejang Lebong?

Dari perumusan masalah di atas, tujuan yang akan dicapai dalam penelitian ini adalah:

1. Menilai indeks dan status keberlanjutan masing-masing dimensi pengelolaan hutan pinus di Taman Nasional Kerinci Seblat Resort Rejang Lebong;

2. Mengidentifikasi faktor-faktor atau atribut-atribut yang sensitif berpengaruh terhadap keberlanjutan pengelolaan hutan pinus di Taman Nasional Kerinci Seblat Resort Rejang Lebong.

Penelitian ini diharapkan dapat menjadi literatur dan informasi dalam studi pengelolaan sumberdaya alam dan lingkungan khususnya pengelolaan hutan pinus di TNKS Resor Rejang Lebong.

\section{METODE PENELITIAN}

Penelitian ini dilaksanakan di Zona Pemanfaatan Hutan MADAPI Taman Nasional Kerinci Seblat (TNKS) Resort Rejang Lebong, Seksi Pengelolaan Taman Nasional Wilayah VI Propinsi Bengkulu dari bulan Juli sampai dengan bulan September 2017.

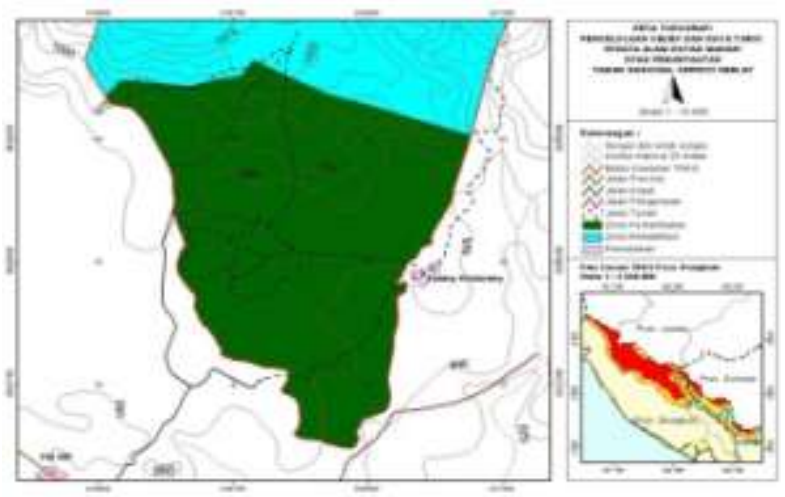

Gambar 1. Peta Zona Pemanfaatan Hutan MADAPI (Desain Tapak Hutan Madapi TNKS Tahun 2017)

Sumber data yang digunakan dalam penelitian ini adalah data primer dan data sekunder. Data primer diperoleh dari survei langsung ke lapangan untuk mendapatkan data fisik dan kuesioner yang digunakan untuk mendapatkan data pendapat dari responden. Sampel yang dijadikan sumber data diambil secara menyeluruh (sensus). Responden dalam penelitian ini sebanyak 20 orang pelaku penyadapan getah pinus. Lokasi penelitian ditentukan secara sengaja yaitu Hutan Madapi TNKS Resort Rejang Lebong. Data sekunder diperoleh melalui studi kepustakaan dan dokumen dari instansi yang terkait dengan penelitian. Peneliti mengambil data sekunder dari Taman Nasional Kerinci Seblat (TNKS) Resort Rejang Lebong.

Metode analisis data keberlanjutan yang digunakan dalam pengelolaan hutan pinus di Taman Nasional Kerinci Seblat (TNKS) Resort Rejang Lebong adalah Multi Dimensional Scaling (MDS) yang kemudian diberi nama RAP-TNKS. Multi Dimensional Scaling (MDS) digunakan untuk mengetahui indeks dan status keberlanjutan serta untuk mengidentifikasi atribut-atribut yang paling sensitif dari masing-masing dimensi keberlanjutan melalui Leverage Analysis. Analisis MDS dengan menggunakan komputer, sekaligus dilakukan analisis Leverage, analisis Monte Carlo, penentuan nilai Stress, dan nilai koefisien determinasi $\left(\mathrm{R}^{2}\right)$.

Analisis Leverage digunakan untuk mengetahui atribut yang sensitif dan intervensi atau perbaikan yang perlu dilakukan. Analisis Monte Carlo dilakukan 
untuk menduga tingkat kesalahan acak (random error) pada model yang dihasilkan dari analisis MDS untuk semua dimensi pada tingkat kepercayaan 95\%. Nilai Stress (S) dan Koefisien determinasi $\left(\mathrm{R}^{2}\right)$ berfungsi untuk menentukan perlu atau tidaknya penambahan atribut dan mencerminkan keakuratan dimensi yang sedang dikaji dengan keadaan sebenarnya di lapangan. Model yang baik atau hasil analisis yang cukup baik apabila menghasilkan nilai Stress kurang dari 0,25 dan nilai $\mathrm{R}^{2}$ mendekati 1 . Skala indeks dan kategori keberlanjutan sistem yang dikaji seperti pada tabel 1 .

Tabel1. Kategori status keberlanjutan pengelolaan hutan pinus di Taman Nasional Kerinci Seblat (TNKS) Resort Rejang Lebong

\begin{tabular}{ll}
\hline \multicolumn{1}{c}{ Nilai Indeks } & \multicolumn{1}{c}{ Kategori } \\
\hline $0,00-25,00$ & Buruk (tidak berkelanjutan) \\
\hline $25,01-50,00$ & Kurang (kurang berkelanjutan) \\
\hline $50,01-75,00$ & Cukup (cukup berkelanjutan) \\
\hline $75,01-100,0$ & Baik (berkelanjutan) \\
\hline
\end{tabular}

\section{HASIL DAN PEMBAHASAN}

Nilai indeks keberlanjutan multi dimensi pengelolaan hutan pinus di Taman Nasional Kerinci Sebelat Resort Rejang Lebong sebesar 56,14\% diperoleh dari penilaian terhadap lima dimensi, yaitu dimensi ekologi, dimensi ekonomi, dimensi sosial budaya, dimensi teknologi dan infrastruktur dan dimensi hukum dan kelembagaan yang secara keseluruhan terdiri dari 50 atribut. Nilai indeks keberlanjutan multi dimensi ini termasuk kedalam kategori cukup berkelanjutan karena nilai tersebut berada pada selang nilai 50,01-75.

Hasil analisis menunjukkan bahwa indeks keberlanjutan dari dimensi ekologi 64,23\% (cukup berkelanjutan); dimensi ekonomi 51,95\% (cukup berkelanjutan); dimensi sosial budaya 54,72\% (cukup berkelanjutan); dimensi teknologi dan infrastruktur 34,81\% (kurang berkelanjutan); dan dimensi hukum dan kelembagaan 74,97\% (cukup berkelanjutan). Nilai indeks dari masing-masing dimensi keberlanjutan disajikan dalam bentuk diagram layanglayang pada gambar 2 .

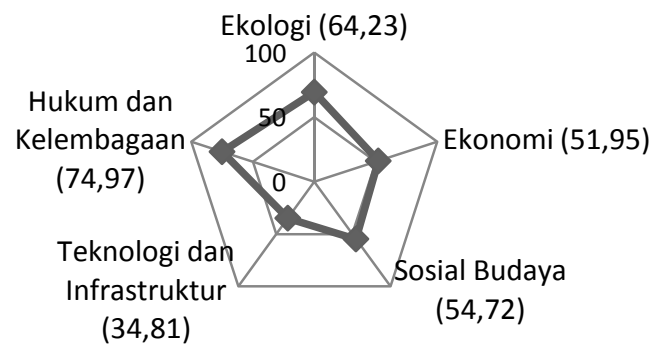

Gambar 2. Indeks keberlanjutan dimensi pengelolaan hutan pinus di Taman Nasional Kerinci Seblat Resort Rejang Lebong

Nilai indeks keberlanjutan pengelolaan hutan pinus di Taman Nasional Kerinci Seblat Resort Rejang Lebong pada dimensi ekologi, dimensi ekonomi, dimensi sosial budaya dan dimensi hukum dan kelembagaan masuk kedalam kategori baik dengan status cukup berkelanjutan, sedangkan dimensi teknologi dan infrastruktur berada pada kategori buruk dengan status kurang berkelanjutan.

Hasil analisis terhadap atribut-atribut dimensi ekologi menunjukkan bahwa indeks keberlanjutan dimensi ekologi sebesar 64,23\% (cukup berkelanjutan), nilai stress $=$ 0,161 dan nilai $R^{2}=0,957$. Menurut Kavanagh (2001), nilai stress yang diperbolehkan apabila kurang dari 0,25. Nilai stress yang lebih kecil, dan nilai $\mathrm{R}^{2}=0,957$ menunjukkan bahwa model yang menggunakan peubah-peubah saat itu sudah menjelaskan $95,7 \%$ dari model yang ada. Nilai indeks keberlanjutan dimensi ekologi tersebut dapat dilihat pada gambar 3 .

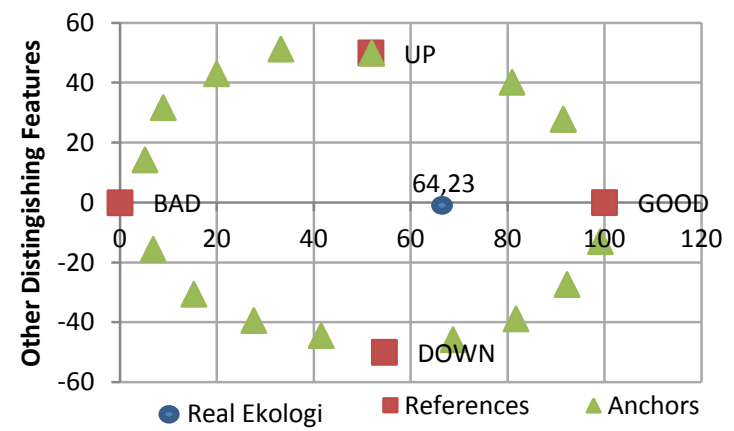

Gambar 3. Analisis Rap-TNKS dimensi ekologi 
Hasil analisis leverage terhadap atributatribut ekologi menunjukkan bahwa semua atribut ekologi sensitif terhadap indeks keberlanjutan. Agar atribut-atribut tersebut dapat ditingkatkan status berkelanjutannya pada masa yang akan datang, maka perlu dilakukan intervensi. Hasil analisis leverage dimensi ekologi selengkapnya dapat dilihat pada gambar 4 .

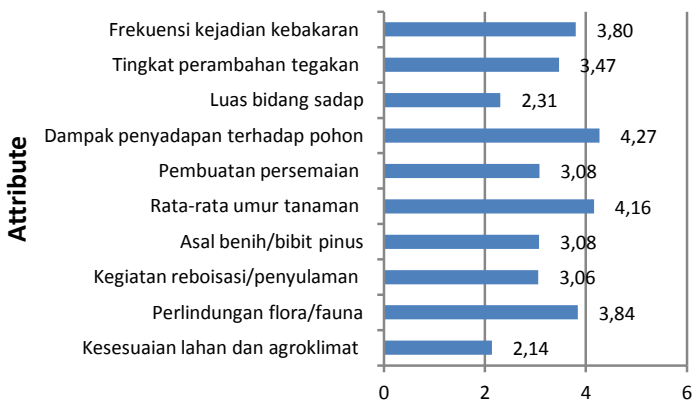

Gambar 4. Sensitivitas atribut dimensi ekologi

Dampak penyadapan terhadap kesehatan pohon pinus merupakan atribut yang paling sensitif mempengaruhi keberlanjutan dimensi ekologi. Penyadapan pinus di lokasi penelitian dilakukan secara koakan dengan cara pembuatan luka sadap sampai pada kayu. Pohon dilukai dengan alat "kedukul" sebanyak 5 sampai 6 koakan per batang sesuai besarnya diameter batang dengan lebar koakan 6-7 cm dan jarak antar koakan 15-25 cm, sehingga total koakan sekitar 20\% keliling pohon.

Menurut Senoaji (2015), agar tidak merusak pohon jumlah koakan maksimum untuk pohon pinus yang berdiameter $60 \mathrm{~cm}$ adalah 4 koakan. Menurut Adhi (2008), kerusakan akibat semakin banyaknya koakan mengakibatkan metabolisme pertumbuhan pohon akan terganggu sehingga diduga dalam jangka waktu yang lama pohon tidak akan tumbuh dengan normal.

Penyadapan getah pinus di hutan konservasi hendaknya menggunakan teknologi yang menimbulkan luka seminimal mungkin untuk menjamin keberlanjutan pengelolaan, seperti dengan tehnik bor atau sadapan bentuk 'V'. Menurut Sukadaryati (2014), beberapa teknik penyadapan pinus secara manual sudah banyak dikembangkan di Perum Perhutani. Perbaikan yang perlu dilakukan untuk meningkatkan indeks dan status keberlanjutan dimensi ekologi ke depan diantaranya: meminimalisasi dampak penyadapan dengan memilih tehnik penyadapan cara lain yang lebih sesuai, meningkatkan biodiversitas pada areal reboisasi, penambahan persemaian, pencegahan kebakaran hutan, penertiban perambah dan penanaman kembali lahan yang telah terlanjur dirambah.

Hasil analisis terhadap atribut-atribut dimensi ekonomi menunjukkan bahwa indeks keberlanjutan dimensi ekonomi sebesar $51,95 \%$ (cukup berkelanjutan), nilai stress $=$ 0,162 dan nilai $R^{2}=0,933$. Nilai stress yang lebih kecil, dan nilai $\mathrm{R}^{2}=0,933$ menunjukkan bahwa model yang menggunakan peubah-peubah saat itu sudah menjelaskan 93,3\% dari model yang ada. Nilai indeks keberlanjutan dimensi ekonomi tersebut dapat dilihat pada gambar 5 .

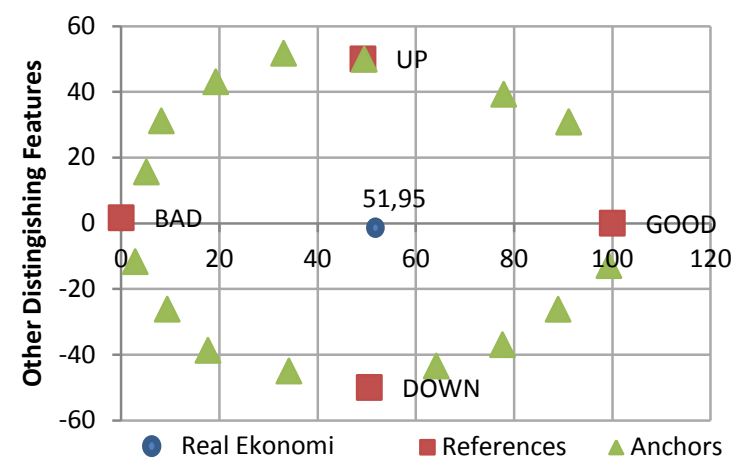

Gambar 5. Analisis Rap-TNKS Dimensi Ekonomi

Hasil analisis leverage menunjukkan bahwa atribut yang sensitif terhadap indeks keberlanjutan pada dimensi ekonomi yang dimulai dari atribut dengan nilai RMS tertinggi. Hasil analisis leverage dimensi ekonomi selengkapnya dapat dilihat pada gambar 6.

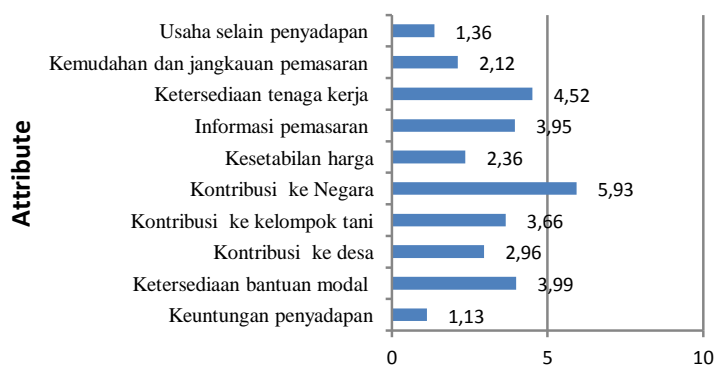

Gambar 6. Sensitivitas atribut dimensi ekonomi 
Kontribusi penyadapan getah pinus ke negara merupakan atribut yang paling sensitif mempengaruhi keberlanjutan dimensi ekonomi. Hasil pengamatan di lokasi penelitian besarnya tarif PSDH sudah mengikuti Peraturan Menteri Kehutanan Nomor : P.68/Menhut-II/2014. Kontribusi pendapatan negara berupa Pendapatan Negara Bukan Pajak (PNBP) sebesar Rp. 42.000 (Empat Puluh Dua Ribu Rupiah) per ton produksi getah masih tergolong sangat rendah. Secara ekonomi kegiatan ini cukup menguntungkan, namun dampak yang ditimbulkan dari pelukaan pohon akibat tehnik penyadapan dengan cara koakan harus diperhitungkan. Perlu dihitung perbandingan besarnya biaya yang harus dikeluarkan oleh negara untuk perbaikan kawasan seandainya terjadi kerusakan dan nilai ekonomi yang diperoleh oleh negara dari kegiatan ini, sehingga kontribusi penyadapan getah pinus ke negara merupakan atribut yang perlu diintervensi. Perbaikan berupa pemberlakuan tarif khusus untuk PSDH getah pinus yang berasal dari hutan konservasi.

Agar dimensi ekonomi ke depan lebih meningkat indeks dan status keberlanjutannya, beberapa tindakan perbaikan yang dapat dilakukan diantaranya penyesuaian provisi hasil hutan, bantuan modal usaha bagi petani penyadap agar mereka dapat mengembangkan usahanya dan kemudahan petani untuk mendapatkan informasi tentang pemasaran getah.

Hasil analisis terhadap atribut-atribut dimensi sosial budaya menunjukkan bahwa indeks keberlanjutan dimensi sosial budaya sebesar $54,72 \%$ (cukup berkelanjutan), nilai stress $=0,148$ dan nilai $\mathrm{R}^{2}=0,944$. Nilai stress yang lebih kecil, dan nilai $\mathrm{R}^{2}=0,944$ menunjukkan bahwa model yang menggunakan peubah-peubah saat itu sudah menjelaskan 94,4\% dari model yang ada. Nilai indeks keberlanjutan dimensi sosial budaya tersebut dapat dilihat pada gambar 7 .

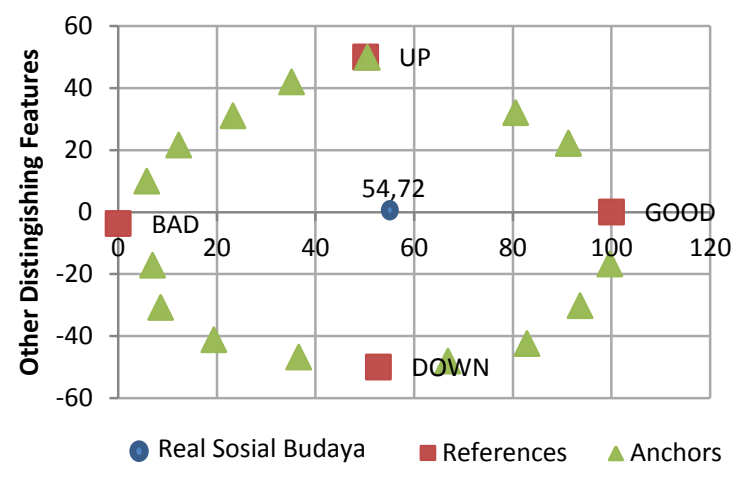

Gambar 7. Analisis Rap-TNKS dimensi sosial budaya

Hasil analisis leverage menunjukkan bahwa ada lima atribut yang sensitif terhadap indeks keberlanjutan pada dimensi sosial budaya adalah (1) tingkat pemberdayaan masyarakat dalam usaha penyadapan getah pinus, (2) fungsi hutan pinus sebagai sarana pendidikan dan penelitian, (3) tingkat penyerapan tenaga kerja usaha penyadapan getah pinus dan (4) fungsi hutan pinus sebagai sarana pariwisata dan (5) alokasi waktu untuk penyadapan getah pinus. Hasil analisis leverage dimensi sosial budaya selengkapnya dapat dilihat pada gambar 8 .

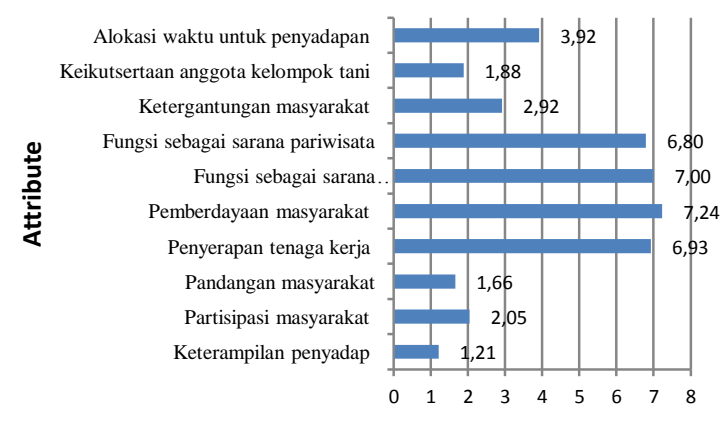

Gambar 8. Sensitivitas atribut dimensi sosial budaya

Tingkat pemberdayaan masyarakat dalam usaha penyadapan getah pinus merupakan atribut yang paling sensitif mempengaruhi keberlanjutan dimensi sosial budaya. Kegiatan penyadapan getah pinus tidak ada pengaruhnya terhadap Masyarakat Desa Karang Anyar Pal VIII yang bekerja selain sebagai penyadap. Kegiatan ini semestinya ke depan ada pengaruh yang positif terhadap usaha masyarakat, misalnya muncul usaha baru dalam bentuk lain atau pengembangan usaha setelah kegiatan ini dilaksanakan. 
Beberapa perbaikan yang dapat dilakukan agar indeks dan status keberlanjutan dimensi sosial budaya dapat lebih berkelanjutan diantaranya: peningkatan pemberdayaan masyarakat, adanya kemudahan publik memasuki kawasan TNKS dalam hal pendidikan, penelitian dan pariwisata dan meningkatkan penyerapan tenaga terutama tenaga kerja lokal.

Hasil analisis terhadap atribut-atribut dimensi teknologi dan infrastruktur menunjukkan bahwa indeks keberlanjutan dimensi teknologi dan infrastruktur sebesar $34,81 \%$ (kurang berkelanjutan), nilai stress $=$ 0,147 dan nilai $R^{2}=0,948$. Nilai stress yang lebih kecil, dan nilai $\mathrm{R}^{2}=0,948$ menunjukkan bahwa model yang menggunakan peubah-peubah saat itu sudah menjelaskan $94,8 \%$ dari model yang ada. Nilai indeks keberlanjutan dimensi teknologi dan infrastruktur tersebut dapat dilihat pada gambar 9 .

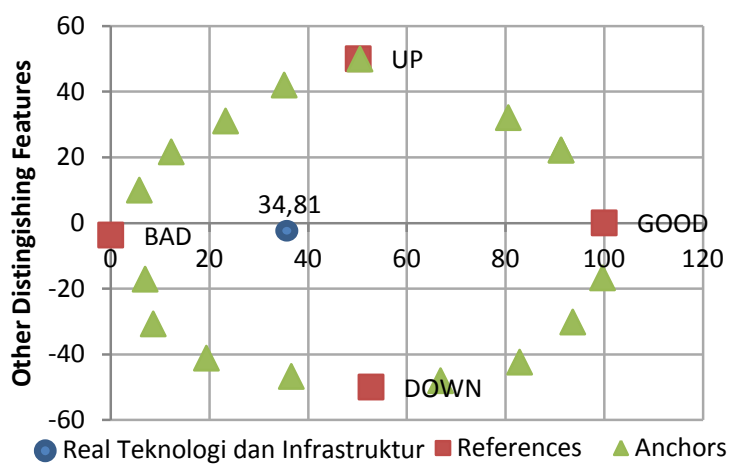

Gambar 9. Analisis Rap-TNKS dimensi teknologi dan infrastruktur

Hasil analisis leverage menunjukkan ada enam atribut yang sensitif terhadap indeks keberlanjutan pada dimensi teknologi dan infrastruktur yang dimulai dari atribut dengan nilai RMS tertinggi. Hasil analisis leverage dimensi teknologi dan infrastruktur selengkapnya dapat dilihat pada gambar 10 .

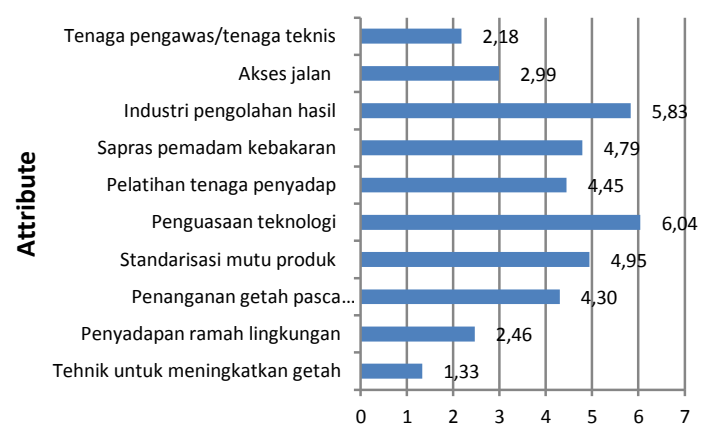

Gambar 10. Sensitivitas atribut dimensi teknologi dan infrastruktur

Tingkat penguasaan teknologi usaha penyadapan getah pinus merupakan atribut yang paling sensitif mempengaruhi keberlanjutan dimensi teknologi dan infrastruktur. Sampai saat ini para penyadap getah pinus lebih memilih menggunakan cara penyadapan kedukul yang dilakukan secara manual atau dengan tenaga manusia, karena cara kedukul ini dirasa lebih praktis, mudah dan murah. Hasil penelitian Sukadaryati (2014), produksi getah pinus paling banyak dihasilkan dari cara penyadapan kedukul yaitu sebesar 18,0 gram per pengunduhan, sedang dengan mujitech dan bor masingmasing sebesar 11,2 gram per pengunduhan dan 11,5 gram per pengunduhan. Kemudian hasil penelitian Hadiyane dkk. (2015), bahwa hasil getah yang disadap dengan cara koakan sebanyak 19,34 gr/pohon, sedangkan dengan cara pengeboran sebesar 32,64 gr/pohon. Teknik penyadapan dengan cara koakan kurang sesuai diterapkan pada pengelolaan hutan pinus di kawasan konservasi meskipun hasil getahnya tinggi karena menimbulkan luka pohon yang lebih besar.

Agar atribut ini ke depan lebih berkelanjutan, hendaknya para pekerja diberi pelatihan untuk menguasai teknologi penyadapan, sehingga hasil produksi yang didapatkan juga akan lebih maksimal. Karena lokasi ini merupakan kawasan konservasi, hendaknya teknologi yang diterapkan merupakan teknologi yang ramah lingkungan, terutama dengan memperhatikan jumlah maksimum koakan per pohon agar fungsi utama kawasan ini sebagai hutan konservasi tetap terjaga. Untuk mengurangi luka pada pohon yang disadap dapat 
dilakukan cara penyadapan dengan sistem pengeboran atau sadapan bentuk "V".

Hasil analisis terhadap atribut-atribut dimensi menunjukkan bahwa indeks keberlanjutan dimensi hukum dan kelembagaan sebesar $74,97 \%$ (cukup berkelanjutan), nilai stress $=0,147$ dan nilai $\mathrm{R}^{2}=0,948$. Nilai stress yang lebih kecil, dan nilai $\mathrm{R}^{2}=0,948$ menunjukkan bahwa model yang menggunakan peubah-peubah saat itu sudah menjelaskan $94,8 \%$ dari model yang ada. Nilai indeks keberlanjutan dimensi hukum dan kelembagaan tersebut dapat dilihat pada gambar 11 .

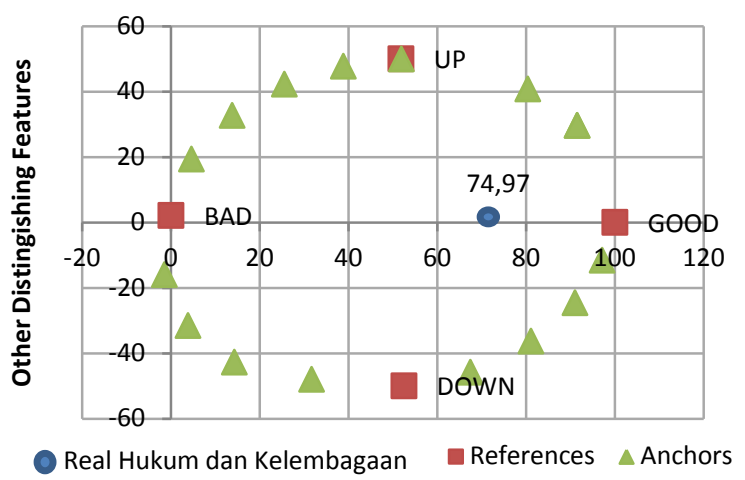

Gambar 11. Analisis Rap-TNKS dimensi hukum dan kelembagaan

Hasil analisis leverage menunjukkan bahwa ada sepuluh atribut yang sensitif terhadap indeks keberlanjutan pada dimensi hukum dan kelembagaan. Hasil analisis leverage dimensi hukum dan kelembagaan selengkapnya dapat dilihat pada gambar 12 .

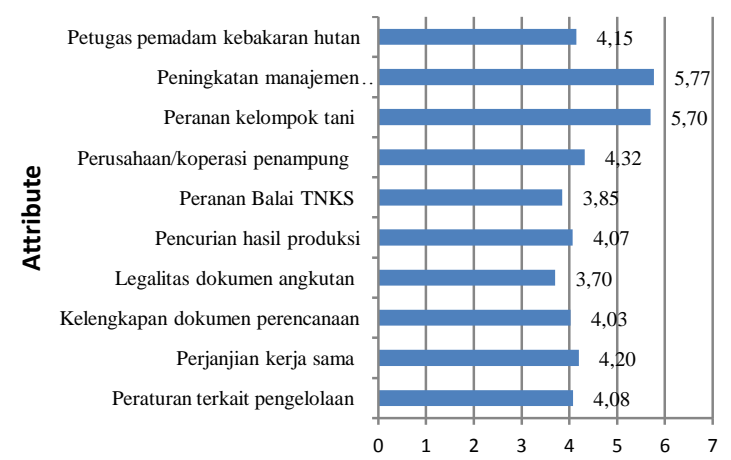

Gambar 12. Sensitivitas atribut dimensi hukum dan kelembagaan

Upaya peningkatan kemampuan manajemen kelembagaan merupakan atribut yang paling sensitif mempengaruhi keberlanjutan dimensi hukum dan kelembagaan. Hasil pengamatan bahwa kelompok tani dalam hal ini Kelompok Tani Bina Karya peranannya masih kurang. Hanya pengurus inti dari kelompok (ketua, sekretaris dan bendahara) yang berperan aktif dalam kegiatan baik secara manajemen maupun sebagai penyadap getah pinus.

Indeks dan status keberlanjutan dimensi hukum dan kelembagaan dapat ditingkatkan dengan melakukan perbaikan diantaranya: meningkatan kemampuan manajemen kelembagaan dan peranan kelompok tani melalui pelatihan penguatan kelembagaan, pembentukan satuan petugas pemadam kebakaran hutan, mencegah terjadinya pencurian getah pinus dan peningkatan peranan TNKS dalam kegiatan usaha.

Amanat Peraturan Pemerintah Nomor 28 Tahun 2011 tentang Pengelolaan Kawasan Suaka Alam (KSA) dan Kawasan Pelestarian Alam (KPA) dan Peraturan Menteri Kehutanan Nomor: P.85/Menhut-II/2014 tentang Tata Cara Kerjasama Penyelenggaraan KSA dan KPA, bahwa bentuk kerjasama dimaksud melalui kolaborasi pemberdayaan masyarakat yang berada di sekitar kawasan hutan. Pasal 49 PP Nomor 28 Tahun 2011 menjelaskan bahwa Pemerintah memberdayakan masyarakat di sekitar KSA dan KPA dalam rangka meningkatkan kesejahteraannya. Kemudian Penyadapan getah pinus oleh kelompok tani sesuai dengan Surat Perjanjian Kerja Sama adalah untuk pemberdayaan masyarakat dalam pemanfaatan dan pengembangan potensi hutan pinus. Hasil penelitian menunjukkan bahwa kegiatan penyadapan getah pinus di zona pemanfaatan Taman Nasional Kerinci Sebelat Resort Rejang Lebong ini belum dapat memberdayakan masyarakat sekitar kawasan secara maksimal. Hal ini dapat dilihat dari jumlah masyarakat lokal sekitar kawasan hutan yang masih sangat sedikit terlibat dalam kegiatan. Pengelolaan hutan bersama masyarakat akan efektif jika para pihak dalam membuat keputusan mengenai hutan dan manfaatnya dilakukan secara partisipatif. Minimnya keterlibatan anggota kelompok tani dalam kegiatan juga menunjukkan bahwa 
pengelolaan kolaboratif penyadapan getah pinus di zona pemanfaatan Taman Nasional Kerinci Sebelat Resort Rejang Lebong belum berjalan seperti yang diharapkan.

Hasil analisis Monte Carlo menunjukkan bahwa pada tingkat kepercayaan 95 persen untuk masing-masing dimensi selisihnya relatif kecil. Hasil analisis Monte Carlo yang menunjukkan nilai indeks keberlanjutan pengelolaan hutan pinus di Taman Nasional Kerinci Seblat Resort Rejang Lebong dapat dilihat pada tabel 2.

Tabel 2. Hasil analisis Monte Carlo untuk nilai keberlanjutan dari masing-masing dimensi.

\begin{tabular}{|c|c|c|c|c|}
\hline \multirow{3}{*}{ Dimensi } & \multicolumn{2}{|c|}{ Indeks } & \multirow{3}{*}{$\begin{array}{c}\text { Selisi } \\
\mathrm{h}\end{array}$} & \multirow{3}{*}{$\begin{array}{c}\text { Stress } \\
(\%)\end{array}$} \\
\hline & \multicolumn{2}{|c|}{ Keberlanjutan } & & \\
\hline & MDS & $\begin{array}{l}\text { Monte } \\
\text { Carlo }\end{array}$ & & \\
\hline Ekologi & 64,23 & 63,19 & 1,04 & 16,1 \\
\hline Ekonomi & 51,95 & 51,76 & 0,19 & 16,2 \\
\hline $\begin{array}{l}\text { Sosial } \\
\text { Budaya }\end{array}$ & 54,72 & 54,30 & 0,42 & 14,8 \\
\hline $\begin{array}{l}\text { Teknologi } \\
\text { dan } \\
\text { Infrastruktur }\end{array}$ & 34,81 & 35,89 & 1,08 & 14,7 \\
\hline
\end{tabular}

Sumber : Data primer diolah Tahun 2017

$\begin{array}{cccc}\text { Hasil analisis } & \text { Monte } & \text { Carlo } \\ \text { menunjukkan } & \text { bahwa nilai } & \text { indeks }\end{array}$ keberlanjutan pengelolaan hutan pinus di Taman Nasional Kerinci Seblat Resort Rejang Lebong pada taraf kepercayaan $95 \%$ menunjukkan hasil yang tidak mengalami perbedaan signifikan dengan hasil MDS. Hal ini menunjukkan bahwa kesalahan analisis dapat diperkecil dalam hal pemberian skor pada setiap atribut keberlanjutan.

\section{KESIMPULAN DAN SARAN}

Status keberlanjutan pengelolaan hutan pinus di Taman Nasional Kerinci Seblat Resort Rejang Lebong secara multidimensi berada pada kategori cukup berkelanjutan $(56,14)$ dengan dimensi ekologi cukup berkelanjutan (64,23\%), dimensi ekonomi cukup berkelanjutan $(51,95 \%)$, dimensi sosial budaya cukup berkelanjutan $(54,72 \%)$, dimensi teknologi dan infrastruktur kurang berkelanjutan $(34,81 \%)$, dan dimensi hukum dan kelembagaan cukup berkelanjutan $(74,97 \%)$. Terdapat 36 atribut yang sensitif mempengaruhi keberlanjutan pengelolaan hutan pinus di Taman Nasional Kerinci Seblat dari 50 atribut yang dianalisis.

Perlu evaluasi pelaksanaan kegiatan oleh kelompok tani pengelola sesuai kesepakatan yang tercantum dalam Surat Perjanjian Kerja Sama (SPKS) agar keseimbangan fungsi hutan baik fungsi ekologi, ekonomi maupun sosial budaya dapat tercapai. Kemudian Perlu adanya pemilihan teknologi penyadapan yang cocok untuk diterapkan pada kawasan konservasi agar fungsi utama hutan konservasi yaitu fungsi ekologi dapat dipertahankan.

\section{DAFTAR PUSTAKA}

Adhi, Y. A. 2008. Pengaruh Jumlah Sadapan Terhadap Produksi Getah Pinus (Pinus merkusii) Dengan Metode Koakan di Hutan Pendidikan Gunung Walat Kabupaten Suka Bumi Jawa Barat. Balai Penelitian Kehutanan Solo. Jawa Tengah. Skripsi. Fakultas Kehutanan Institut Pertanian Bogor. Bogor.

Hadiyane A. Sulistyawati E. Asharina WP. And Dungani R. 2015. A Study on Production of Resin from Pinus merkusii Jungh. Et De Vriese in the Bosscha Observatory Area, West JavaIndonesia. Asian Joirnal of Plant Sciences.

Kavanagh P. And T.J. Pitcher. 2004. Implementing Microsoft Excel Sofware For Fish: A echnique for The Rapid Appraisal of Fisheries Status. University of British Columbia. Fisheries Centre Research Report.

Pitcer, T.J and Preikshot, D. 2001. Rapfish: Arapid Appraisal Technique to Evaluate The Sustainability Status of Fisheries. Fisheries Research.

Senoaji G. 2015. Akademisi Soroti Pemanenan Getah Pinus Bengkulu. Antara Bengkulu. Bengkulu.

Supriadi. 2011. Hukum Kehutanan dan Hukum Perkebunan di Indonesia. Sinar Grafika. Jakarta.

Sukadaryati. 2014. Pemanenan Getah Pinus Menggunakan Tiga Cara Penyadapan. Pusat Penelitian dan Pengembangan Keteknikan Kehutanan dan Pengolahan Hasil Hutan. Bogor. Jurnal Penelitian Hasil Hutan Vol. 32 No. 1, Maret 2014 